\title{
EMPREGO DE METODOLOGIA ENZIMÁTICA NA OBTENÇÃO DE EXTRATOS PROTÉICOS DE FARINHA DE TRIGO
}

\author{
Raquel Linhares Carreira, Camila Salles Ramos, Mauro Ramalho Silva, Carlos de Oliveira Lopes Junior e \\ Marialice Pinto Coelho Silvestre* \\ Departamento de Alimentos, Faculdade de Farmácia, Universidade Federal de Minas Gerais, Av. Antônio Carlos 6627, $31270-901$ \\ Belo Horizonte - MG, Brasil \\ Mônica Ribeiro Pirozi \\ Departamento de Tecnologia de Alimentos, Universidade Federal de Viçosa, Campus Universitário, 36570-000 Viçosa - MG, \\ Brasil
}

Recebido em 6/5/08; aceito em 17/10/08; publicado na web em 12/2/09

\begin{abstract}
USE OF AN ENZYMATIC METHOD FOR OBTAINING PROTEIN EXTRACTS FROM WHEAT FLOUR. An enzymatic method was used for obtaining protein extracts from wheat flour using an alkaline protease. Some parameters were evaluated aiming the optimization of this method: temperature $\left(40-50^{\circ} \mathrm{C}\right)$; time $(2-5 \mathrm{~h})$; physical treatment of the sample (no treatment, ultra-turrax $/ 16,000$ $\mathrm{rpm} / 5 \mathrm{~min}$ and ultrasound/120 W/10 min); enzyme:substrate ratio (E:S) of 5:100 - 10:100 and concentration of wheat flour (1:3, 1:5 and 1:10 w/v). The results showed that the best condition for protein extraction was that using the sample concentration of 1:3 (w/v), ultra-turrax, E:S of 10:100, at $40^{\circ} \mathrm{C}, 2 \mathrm{~h}$, having reached an extraction yield of $88.53 \%$.
\end{abstract}

Keywords: cereal; wheat flour; protein extraction.

\section{INTRODUÇÃO}

O trigo, juntamente com o arroz e o milho, é um dos mais importantes grãos de cereais no mundo, fornecendo nutrientes para seres humanos e animais e servindo como material básico para a produção de amido, óleo e proteína, bebidas alcoólicas, adoçantes e, mais recentemente, como combustível. ${ }^{1}$ No Brasil, consomem-se cerca de 8,5 milhões de toneladas de trigo ao ano e destas, $25 \%$ tornam-se farelo que, em parte, abastece a indústria de ração. Os $75 \%$ restantes (cerca de 6,3 milhões de toneladas) são destinados a atender os mercados de massas, pães, bolos, doces e biscoitos.

As proteínas do trigo são divididas em dois grupos, um deles formado pelas albuminas (solúveis em água) e globulinas (solúveis em solução salina), representando $15 \%$ das proteínas totais, sendo chamadas de proteínas solúveis e, o outro, formado pela gliadina (solúveis em álcool) e glutenina (solúveis em álcalis) que compreendem os restantes $85 \%$ das proteínas..$^{2-5}$ A gliadina e glutenina combinadas possuem a propriedade de formar, juntamente com a água e a aplicação de energia mecânica, uma rede tridimensional viscoelástica, insolúvel em água, denominada glúten. ${ }^{6}$ Em virtude da grande importância em tecnologia dos cereais, as proteínas do glúten têm sido bastante estudadas. ${ }^{3}$

O método usado para isolar as proteínas tem efeitos importantes nas suas propriedades. ${ }^{7} \mathrm{O}$ tratamento alcalino apresenta inúmeros inconvenientes, tais como, desnaturação protéica, formação de compostos tóxicos (lisinoalanina), escurecimento da amostra e extração de compostos não-protéicos. ${ }^{8}$ Uma alternativa seria o emprego de enzimas para extrair as proteínas. Na literatura, foram encontrados alguns trabalhos empregando a extração enzimática de proteínas do arroz $^{9,10}$ e soja, ${ }^{11}$ nos quais o interesse dos autores estava voltado para a separação das proteínas destes alimentos. Em outros casos, a utilização deste método estava associada à separação do amido de arroz. ${ }^{7,12,13}$

*e-mail: malice@ farmacia.ufmg.br
Em estudos realizados anteriormente no Laboratório de Bromatologia/ Pesquisa da Faculdade de Farmácia da UFMG, onde foi desenvolvido o presente trabalho, foi empregado o método enzimático para extração de proteínas do arroz em grão, ${ }^{14}$ do fubá de milho ${ }^{15}$ e de uma farinha de arroz comercial, ${ }^{16}$ tendo sido encontrados rendimentos que variaram de 63 a $88 \%$, dependendo das condições empregadas. $\mathrm{O}$ efeito do tratamento físico da amostra (ultra-turrax, ultra-som e outros) foi, igualmente, avaliado neste mesmo laboratório, ${ }^{16}$ assim como por outros autores. ${ }^{10,17}$ Os resultados obtidos foram variados, dependendo da matéria-prima e dos parâmetros utilizados.

Este trabalho envolveu a determinação da composição química e a otimização da extração protéica da farinha de trigo, empregando-se um método enzimático e testando-se diferentes condições de extração e tratamento da amostra.

\section{PARTE EXPERIMENTAL}

\section{Material}

A farinha de trigo tipo I foi adquirida no comércio de Belo Horizonte, MG. A protease Protemax ${ }^{\circledR} 580$ L (EC 3.4.21.14, uma serino-endopeptidase de origem bacteriana - cepa do Bacillus licheniformis, atividade $580 \mathrm{KDU} / \mathrm{g}$, estável em pH entre 7 e $10 \mathrm{com} \mathrm{pH}$ ótimo em 9,5 , temperatura ótima de $60^{\circ} \mathrm{C}$ e temperatura de inativação acima de $85^{\circ} \mathrm{C}$ por $10 \mathrm{~min}$ ) foi adquirida da Prozyn (São Paulo, SP, Brasil). Empregou-se o ultra-turrax (IKA Labortechnix, T25 basic, Wilmington, EUA) e o ultra-som (Thornton, T14, Vinhedo, São Paulo, Brasil). Os demais reagentes foram de grau analítico.

\section{Métodos}

Determinação da composição química da farinha de trigo

A farinha de trigo tipo I foi acondicionada em potes de vidro, hermeticamente fechados e mantidos sob refrigeração, até o momento de uso. 
Todas as análises da composição química da matéria-prima foram realizadas em triplicata, segundo as metodologias descritas pela Association of Official Analytical Chemists. ${ }^{18} \mathrm{~A}$ umidade foi determinada pelo método de secagem em estufa ventilada (Quimis Q-314M242, série 020 , Diadema, $\mathrm{SP}$ ) a $105^{\circ} \mathrm{C}$ até peso constante; as cinzas ou minerais, por incineração, em mufla a $550{ }^{\circ} \mathrm{C}$; os lípides, por extração com éter etílico, Soxhlet modificado (Quimis Q-308G26, série 018, Diadema, SP); as proteínas foram determinadas pelo método de micro-kjeldahl, as fibras alimentares pelo método enzimático e os carboidratos, por diferença. O fator de conversão de nitrogênio para proteína usado foi 5,70 , para cereais em geral. ${ }^{19}$

\section{Extração enzimática das proteínas da farinha de trigo tipo I}

Empregou-se um método de extração enzimática das proteínas da farinha de trigo tipo I, ${ }^{17} \mathrm{com}$ algumas modificações introduzidas no Laboratório de Bromatologia/Pesquisa da Faculdade de Farmácia da UFMG. ${ }^{15,16}$ Algumas adaptações adicionais foram realizadas visando aumentar o rendimento de extração protéica (REP), tais como tempo e temperatura empregados, relação E:S, concentração da matéria-prima, além da associação ou ausência do tratamento físico.

A farinha de trigo tipo I foi suspensa em água destilada na proporção de 1:3, 1:5 e 1:10. O benzoato de sódio foi adicionado em quantidade necessária para obter uma concentração final de $0,1 \%$ $(\mathrm{p} / \mathrm{v})$. Parte da suspensão foi submetida a um tratamento físico com ultra-turrax (16.000 rpm, $5 \mathrm{~min}$ ) ou ultra-som (120 V, $10 \mathrm{~min}$ ). Outra parte não sofreu qualquer tratamento. A enzima (protease do Bacillus licheniformis) foi, então, adicionada para se obter as relações E:S de 5:100 e 10:100. O pH foi ajustado para 9,5 com solução de $\mathrm{NaOH}$ a 3 $\mathrm{mol} / \mathrm{L}$ e a mistura foi colocada em banho de vaselina, sobre agitador magnético, às temperaturas de 40 e $50^{\circ} \mathrm{C}$, por 2 e $5 \mathrm{~h}$. Em seguida, a suspensão foi resfriada até $25^{\circ} \mathrm{C}$ e centrifugada por $15 \min$ a $1700 \mathrm{x}$ g. O extrato (EPFT) foi recolhido, separadamente, em um recipiente e o resíduo foi, então, lavado duas vezes com água destilada, repetindose a etapa de centrifugação entre as lavagens e recolhendo sempre o EPFT no mesmo recipiente. O resíduo foi pesado e submetido à determinação do teor de proteína.

\section{Determinação do rendimento da extração protéica}

Para cada parâmetro estudado, o rendimento da extração protéica (REP) foi calculado, conforme a Equação 1:

$$
\mathrm{REP}=\frac{[(\mathrm{AxB})-(\mathrm{C} \times \mathrm{D})]}{(\mathrm{A} \times \mathrm{B})} \times 100
$$

$\mathrm{A}=$ teor de proteína na farinha de trigo tipo I; $\mathrm{B}=$ quantidade de farinha de trigo tipo I utilizada na extração; $\mathrm{C}=$ peso de resíduo obtido na extração; $\mathrm{D}=$ teor de proteína no resíduo.

\section{Análise estatística}

Todos os experimentos foram feitos em três repetições, no mesmo dia, e as análises foram realizadas em triplicata. Utilizou-se a análise de variância (ANOVA fator único) e o teste de Duncan a $5 \%$ de probabilidade, para comparar o REP em relação ao efeito dos parâmetros empregados na extração enzimática das proteínas de farinha de trigo tipo $\mathrm{I}^{20}$

\section{RESULTADOS E DISCUSSÃO}

\section{Composição química da matéria-prima}

Encontram-se na Tabela 1 os resultados obtidos para os teores dos componentes da farinha de trigo tipo I. De maneira geral, os valores encontrados estão próximos dos citados na literatura e assemelham- se aos do rótulo da matéria-prima. Apesar do teor de umidade estar um pouco mais elevado, o valor máximo permitido pela legislação brasileira é de $15 \%$ estando, portanto, abaixo deste limite. ${ }^{21} \mathrm{O}$ teor protéico da farinha de trigo tipo I utilizada $(8,57 \%)$ apresentou-se inferior ao teor encontrado na literatura $(9,8 \%) .{ }^{22} \mathrm{O}$ teor de cinzas encontrado $(0,75 \%)$ apresentou-se cerca de duas vezes superior ao relatado na tabela da FAO $(0,4 \%) .{ }^{23}$ Entretanto, nesta referida tabela não havia menção sobre o grau de refinamento da farinha descrita. Esta variação na composição química de um alimento pode estar relacionada às condições de cultivo, clima, solo e adubação. Além disso, as diferenças relatadas acima poderiam estar associadas ao fato de que os métodos empregados na determinação destes componentes podem ter influenciado nos resultados obtidos, ${ }^{2}$ embora não tenham sido mencionados na literatura consultada.

Tabela 1. Composição química da farinha de trigo tipo I

\begin{tabular}{lcccc}
\hline Componentes & $\begin{array}{c}\text { Valores obtidos } \\
\text { em MI* }\end{array}$ & TACO $^{22}$ & FAO $^{23}$ & Rótulo $^{* *}$ \\
\hline Umidade & 13,68 & 13 & 12 & - \\
Proteína & 8,57 & 9,8 & 8,6 & 10 \\
Lípides & 1,29 & 1,4 & 1,0 & 1 \\
Cinzas totais & 0,75 & 0,8 & 0,4 & - \\
Fibra Alimentar & 2,4 & 2,3 & 2,1 & 2,0 \\
Total & 86,96 & 75 & 73,9 & 76 \\
Carboidratos & & & & \\
\hline
\end{tabular}

*Valores obtidos neste trabalho, dados em matéria integral (MI); ${ }^{22}$ dados tabela TACO; ${ }^{23}$ dados tabela FAO; ${ }^{* *}$ produto adquirido no comércio em Belo Horizonte.

\section{Eficiência da extração enzimática das proteínas}

Na Tabela 2 são apresentados os resultados do rendimento da extração enzimática das proteínas da farinha de trigo encontrados. Como se pode observar, os maiores resultados foram obtidos para os extratos 4 e 8 , cujo valor médio atingiu 93,26\%, para os quais foram empregadas condições diferentes de extração, especialmente no que refere ao tipo de tratamento físico da amostra e concentração da matéria-prima. A extração incompleta das proteínas e conseqüente redução de REP, provavelmente, deve-se à interferência da matriz, devido às interações com outros constituintes da amostra, tais como lípides e carboidratos. ${ }^{11}$

Levando-se em conta que o extrato protéico será utilizado em uma etapa posterior para o desenvolvimento de alimento para fins dietéticos especiais, à base de farinha de trigo, os atributos sensoriais do extrato devem, igualmente, ser levados em consideração. Observou-se que o emprego tanto de temperatura $\left(55^{\circ} \mathrm{C}\right.$ - extrato 10$)$ quanto de tempo mais elevados $(5 \mathrm{~h}$ - extratos 2 e 10$)$ acarretou escurecimento dos extratos. Por outro lado, extratos obtidos a $40^{\circ} \mathrm{C}$ e $2 \mathrm{~h}$ de reação apresentaram uma coloração mais clara. Dessa forma, apesar dos extratos protéicos mencionados acima (4 e 8) terem apresentado o maior rendimento de extração (média de $93,26 \%$ ), a melhor condição foi a que produziu o EPTF 9 pois, apesar de não ter apresentado o maior valor de REP, o rendimento foi elevado $(88,53 \%)$ e, ainda, empregou-se a maior relação MP: água (1:3), o que é economicamente mais vantajoso para adaptação do processo em larga escala.

Em trabalhos semelhantes, realizados no Laboratório de Bromatologia/Pesquisa da Faculdade de Farmácia da UFMG, Capobiango et al. ${ }^{15}$ empregaram uma protease alcalina de $B$. Licheniformis para extrair as proteínas do fubá de milho, obtendo um REP de $86,8 \%$ e para a extração das proteínas de uma farinha de arroz comercial, 
Tabela 2. Rendimento da extração enzimática das proteínas da farinha de trigo

\begin{tabular}{|c|c|c|}
\hline Amostras & Parâmetros da extração & $\begin{array}{c}\text { Rendimento de } \\
\text { extração (\%) }\end{array}$ \\
\hline EPFT 1 & $40{ }^{\circ} \mathrm{C}, 2$ h, UT, E:S 10:100, MP 1:5 p/v & $85,44^{\mathrm{c}}$ \\
\hline EPFT 2 & $40^{\circ} \mathrm{C}, 5 \mathrm{~h}, \mathrm{UT}, \mathrm{E}: \mathrm{S} 10: 100, \mathrm{MP} 1: 5 \mathrm{p} / \mathrm{v}$ & $85,12^{\mathrm{c}}$ \\
\hline EPFT 3 & $40^{\circ} \mathrm{C}, 2 \mathrm{~h}, \mathrm{STF}, \mathrm{E}: \mathrm{S}$ 10:100, MP 1:5 p/v & $89,05^{\mathrm{b}}$ \\
\hline EPFT 4 & $40{ }^{\circ} \mathrm{C}, 2 \mathrm{~h}, \mathrm{US}, \mathrm{E}: \mathrm{S}$ 10:100, MP 1:5 p/v & $91,58^{\mathrm{a}, \mathrm{b}}$ \\
\hline EPFT 5 & $40^{\circ} \mathrm{C}, 2 \mathrm{~h}$, UT,E:S 5:100, MP 1:10 p/v & $84,67^{c}$ \\
\hline EPFT 6 & $40{ }^{\circ} \mathrm{C}, 2$ h, UT, E:S 5:100, MP 1:5 p/v & $85,29^{\mathrm{c}}$ \\
\hline EPFT 7 & $40{ }^{\circ} \mathrm{C}, 2$ h, UT, E:S 5:100, MP 1:3 p/v & $80,35^{\mathrm{d}}$ \\
\hline EPFT 8 & $40^{\circ} \mathrm{C}, 2 \mathrm{~h}, \mathrm{UT}, \mathrm{E}: \mathrm{S}$ 10:100, MP 1:10 p/v & $94,94^{\mathrm{a}}$ \\
\hline EPFT 9 & $40{ }^{\circ} \mathrm{C}, 2$ h, UT, E:S 10:100, MP 1:3 p/v & $88,53^{\mathrm{b}}$ \\
\hline EPFT 10 & $55^{\circ} \mathrm{C}, 5$ h, UT, E:S 10:100, MP 1:5 p/v & $76,93^{\mathrm{e}}$ \\
\hline
\end{tabular}

$\mathrm{EPFT}=$ Extrato protéico da farinha de trigo. $\mathrm{STF}=$ sem tratamento físico, UT = Ultra-turrax $5 \mathrm{~min}, \mathrm{US}=$ Ultrasom $10 \mathrm{~min}, \mathrm{MP}=$ relação matéria-prima:água. Os resultados representam médias de triplicatas. Médias indicadas por letras iguais não diferem entre si a $5 \%$ de significância.

Vieira et al. ${ }^{16}$ testaram duas proteases, sendo uma alcalina (de $B$. Licheniformis) e outra neutra (de Bacillus subtilis); o maior REP, de $63,4 \%$, foi obtido com a primeira enzima. ${ }^{16} \mathrm{~A}$ análise do conjunto destes resultados demonstra que os rendimentos de extração protéica são variáveis em produtos de diferentes tipos de cereais.

\section{Efeito dos parâmetros na extração enzimática das proteínas}

\section{Efeito da temperatura de reação}

Para verificar o efeito da temperatura no rendimento da extração das proteínas de farinha de trigo, deve-se comparar o extrato 2 com o 10 (40 e $55^{\circ} \mathrm{C}$, respectivamente). Pode-se observar na Tabela 2 que a temperatura afetou o rendimento da extração, uma vez que houve diferença significativa entre os resultados.

Além disso, o efeito desejável associando o emprego de uma menor temperatura com um maior rendimento, relacionado à redução de custos do processo, foi observado, pois o REP a $40{ }^{\circ} \mathrm{C}(85,12 \%)$ foi superior ao obtido a $55^{\circ} \mathrm{C}(76,93 \%)$. Este resultado poderia ser explicado pelo fato de que o valor mais elevado de temperatura está dentro da faixa de gelatinização do amido do trigo $\left(55-65^{\circ} \mathrm{C}\right)$, na qual parte das proteínas ligadas às moléculas de amido poderia estar inacessível à ação da enzima, ${ }^{3}$ o que reduziria a eficiência da extração enzimática.

Em trabalhos anteriores realizados no Laboratório de Bromatologia/Pesquisa da Faculdade de Farmácia da UFMG, empregando a mesma protease alcalina de origem microbiana do presente trabalho, Capobiango et al. ${ }^{15}$ utilizando fubá de milho e Vieira et al. ${ }^{16}$ a farinha de arroz comercial também observaram valores superiores de REP com o emprego de uma menor temperatura, tendo obtido $83,8 \%$ a $55^{\circ} \mathrm{C}$ e $81,2 \%$ a $60{ }^{\circ} \mathrm{C}$ e $53,5 \%$ a $50{ }^{\circ} \mathrm{C}$ e $50,7 \%$ a $60{ }^{\circ} \mathrm{C}$, respectivamente.

\section{Efeito do tempo de reação}

Para avaliar o efeito do tempo no rendimento de extração das proteínas foram comparados entre si os extratos 1 (2 h) e 2 (5 h). Não houve diferenças significativas entre estes dois tratamentos empregados, sendo o REP de 85,12 e 82,76\%, para 2 e 5 h de hidrólise, respectivamente. Este resultado não está de acordo com o esperado teoricamente, ou seja, o emprego de um maior tempo de ação da enzima não foi suficiente para elevar o rendimento de extração. Provavelmente, o tempo de $5 \mathrm{~h}$ não promoveu uma hidrólise mais acentuada da molécula protéica com a formação de peptídeos de cadeias mais curtas, que são mais solúveis. ${ }^{11}$ Por outro lado, o tempo de $2 \mathrm{~h}$ apresentou algumas vantagens sobre o de $5 \mathrm{~h}$, uma vez que produziu um extrato com menor coloração, que é uma característica importante para a qualidade física do produto final, como citado acima. Outra vantagem de se utilizar $2 \mathrm{~h}$, em vez de $5 \mathrm{~h}$, para a extração protéica está associada a um menor risco de contaminação microbiana, além de contribuir para redução de custos, especialmente, no caso da aplicação do processo em larga escala.

\section{Efeito do tipo do tratamento físico da amostra}

Para avaliar este parâmetro, foram comparados os extratos 1 (ultra-turrax), 4 (ultra-som) e 3 (sem tratamento físico). Observa-se na Tabela 2 que não houve diferenças significativas entre os valores de REP dos extratos obtidos com ultra-som $(91,58 \%)$ e sem tratamento físico $(89,05 \%)$. Por outro lado, o extrato obtido com o emprego de ultra-turrax apresentou valor inferior de $\operatorname{REP}(85,44 \%)$.

Em trabalho anterior do Laboratório de Bromatologia/Pesquisa da Faculdade de Farmácia da UFMG, Vieira et al. ${ }^{16}$ observaram que o tipo de tratamento empregado no processo de extração enzimática das proteínas da farinha de arroz, pela ação da mesma protease alcalina de origem microbiana utilizada, não influenciou o REP, ao se comparar diferentes tempos de ação do ultra-turrax cujo valor médio foi de $57,6 \%$ com os extratos para os quais se empregou o ultra-som com tempos diferentes de ação, tendo obtido o valor médio de 55,0\%.

\section{Efeito da relação enzima: substrato e da concentração da matéria- prima}

Pode-se avaliar o efeito da relação E:S comparando-se os extratos com valores de E:S de 5:100 com os de 10:100 (7 com 9; 6 com 1; 5 com 8). Verifica-se na Tabela 2 que, para as concentrações de matéria-prima de 1:3 e 1:10 p/v, o emprego de maior relação E:S foi mais vantajoso, pois levou ao maior REP, tendo os valores variado de $80,35 \%$ (EPFT 7) para 88,53\% (EPFT 9), e 84,67\% (EPFT 5) para 94,94\% (EPFT 8). Por outro lado, a relação E:S não afetou o REP dos extratos preparados na concentração de matéria-prima de 1:5 p/v, pois não houve diferenças significativas ente os valores obtidos para E:S de 5:100 (85,29\%) e de 10:100 (85,44\%).

Em trabalho anterior com farinha de arroz, realizado no Laboratório de Bromatologia/Pesquisa da Faculdade de Farmácia da UFMG, foi obtido por Vieira et al., ${ }^{16}$ ao contrário do presente trabalho, maior valor de REP ao se usar E:S de 5:100 quando comparado com 10:100, para todas as concentrações de matéria-prima utilizadas (1:3, 1:5 e $1: 10 \mathrm{p} / \mathrm{v})$. Assim, os valores variaram de 43,7 para 47,9\%, de 53,6 para $60,3 \%$ e de 57,8 para 63,4\% para 5:100 e 10:100, respectivamente.

Para avaliar o efeito da concentração de matéria-prima no REP, devem ser comparados, entre si, os extratos preparados com E:S de 5:100 (7, 6 e 5) e de 10:100 (9, 1 e 8). No primeiro caso, observa-se na Tabela 2 que, ao se utilizar uma menor relação MP:água (maior diluição da amostra), houve um aumento do REP, comparando-se $1: 3(80,35 \%$ - EPFT 7) e 1:5 (85,29\% - EPFT 6). Por outro lado, o mesmo não ocorreu quando se diluiu ainda mais a amostra, ao se comparar 1:5 com 1:10 (84,67 e 76,93\%, respectivamente), pois não foi observada diferença significativa entre os valores obtidos. Para as amostras preparadas com E:S de 10:100, observou-se que, quanto maior a diluição da amostra mais elevado foi o rendimento de extração, pois, como mostrado na Tabela 2, os valores obtidos para o REP foram de 88,53, 85,44 e 94,94\%, para as relações MP:água de 1:3, 1:5 e 1:10, respectivamente. Observa-se, ainda, na Tabela 2 que os maiores valores de REP foram obtidos com E:S de 10:100, tanto para 
MP:água de 1:5 quanto de 1:10 (91,58 e 94,94\%, respectivamente).

Vieira et al., ${ }^{16}$ realizando trabalho no Laboratório de Bromatologia/ Pesquisa da Faculdade de Farmácia da UFMG, com farinha comercial de arroz, relataram que quanto maior a diluição da amostra mais elevado foi o rendimento de extração, para os dois valores de E:S empregados, ou seja, de 5:100 e 10:100, ao contrário do observado neste trabalho. Por outro lado, o maior valor de REP foi obtido com a mesma E:S deste trabalho (10:100), porém com a amostra mais diluída (1:10).

Ressalta-se, ainda, que não foram encontrados na literatura estudos abordando o efeito deste parâmetro sobre o REP em produtos à base de trigo.

\section{CONCLUSÕES}

O estudo do efeito de diversos parâmetros utilizados na extração enzimática com uma protease alcalina mostrou que o emprego do tratamento físico da amostra, a ação da temperatura, do tempo de extração, da concentração da amostra e da relação E:S influenciaram de forma variada no rendimento de extração protéica (REP). Considerando-se, não apenas o valor do REP, mas também o aspecto físico do extrato protéico, o melhor resultado $(88,53 \%)$ foi obtido ao se utilizar a concentração inicial de matéria-prima a 1:3 (p/v), tratamento físico com ultra-turrax a $16.000 \mathrm{rpm}$ por $5 \mathrm{~min}$, relação $\mathrm{E}: \mathrm{S}$ de $10: 100$, a $40^{\circ} \mathrm{C}$, por $2 \mathrm{~h}$.

\section{AGRADECIMENTOS}

À Fapemig, à CAPES e ao CNPq pelo apoio financeiro a este trabalho, nas formas de auxílio à pesquisa e bolsas de Doutorado e Iniciação Científica.

\section{REFERÊNCIAS}

1. FAO - Food and Agriculture Organization; Maize in Human Nutrition, FAO: Rome, 1992.

2. http://www.fao.org/inpho/content/documents//vlibrary/t0567e/ T0567E00.htm, acessada em Abril 2008.
3. Esteller, M. S.; Dissertação de Mestrado, Universidade de São Paulo, Brasil, 2004.

4. Hamada, J. S.; Cereal Chem. 1997, 74, 662.

5. Ju, Z. Y.; Hettiarachchy, N. S.; Rath, N.; J. Food Sci. 2001, 66, 229.

6. Bobbio, F. O.; Bobbio, P. A.; Introdução à química de alimentos, $3^{\mathrm{a}}$ ed., Varela: São Paulo, 2003.

7. Agboola, S.; Ng, D.; Mills, D.; J. Cereal Sci. 2005, 41, 283.

8. Wang, M.; Hettiarachchy, N. S.; Qi, M.; Burks, W.; Siebenmorgen, T.; J. Agric. Food Chem. 1999, 47, 411.

9. Euber, J. R.; Puski, G.; Hartman Jr., G. H.; Bristol-Myers Company., U.S. Patent 4,990,344. 1991

10. Tang, S.; Hettiarachchy, N. S.; Shellhammer, T. H.; J. Agric. Food Chem. 2002, 50, 7444 .

11. Fischer, M.; Kofod, L. V.; Schols, H. A. S.; Piersma, S. R.; Gruppen, H.; Voragen, A. G. J.; J. Agric. Food Chem. 2001, 49, 4463.

12. Wang, L.; Wang, Y. J.; J. Cereal Sci. 2004a, 39, 291.

13. Wang, L.; Wang, Y. J.; Cereal Chem. 2004b, 81, 140.

14. Bizzotto, C. S.; Capobiango, M.; Biasutti, E. A. R.; Silva, V. D. M.; Junqueira, R. G.; Silvestre, M. P. C.; Ciênc. Agrotec. 2006, 30, 308.

15. Capobiango, M.; Vieira, C. R.; Santiago e Silva, A. L.; Coelho, J. V.; Segall, S. D.; Silvestre, M. P. C.; Ciênc. Tecnol. Aliment. 2006, 26, 884.

16. Vieira, C. R.; Lopes Jr., C. O.; Ramos, C. S.; Capobiango, M.; Silvestre, M. P. C.; Ciênc. Tecnol. Aliment. 2008, 27, 599.

17. Wang, L.; Wang, Y. J.; Cereal Chem. 2001, 78, 690.

18. AOAC - Association of Official Agricultural Chemists; Official methods of analysis of AOAC international, $16^{\text {th }}$ ed., Arlington: AOAC International, 1995.

19. Nielsen, S. S.; Food analysis, Aspen Publisher: Gaithersburg, 1998.

20. Pimentel-Gomes, F.; Curso de estatística experimental, $14^{\mathrm{a}}$ ed., Oxford: Piracicaba, 2000.

21. http://www.engetecno.com.br/legislacao/cereais_farinha_trigo.htm, acessada em Abril 2008.

22. http://www.unicamp.br/nepa/taco/contar/taco_versao2.pdf, acessada em Abril 2008.

23. FAO - Food and Agriculture Organization; Food Balance Sheet., FAO: 2002. 